\title{
The health, economic, and social effect of COVID-19 and its response on gender and sex: A literature review
}

Hannah Briggs

Thoai Ngo

Population Council

Follow this and additional works at: https://knowledgecommons.popcouncil.org/departments_sbsr-pgy

Part of the Social and Behavioral Sciences Commons How does access to this work benefit you? Let us know!

\section{Recommended Citation}

Briggs, Hannah and Thoai Ngo. 2020. "The health, economic, and social effect of COVID-19 and its response on gender and sex: A literature review," COVID-19 Research \& Evaluations study description. New York: Population Council. 
Title: The health, economic, and social effect of COVID-19 and its response on gender and sex: a literature review

Date: June 3, 2020

Authors: Hannah E Briggs ${ }^{1}$, Thoai D Ngo ${ }^{2}$

Affiliations:

${ }^{1}$ Columbia University, Mailman School of Public Health, New York, NY, USA

${ }^{2}$ Poverty, Gender, and Youth Program, Population Council, New York, NY, USA

\title{
Contacts:
}

Thoai D Ngo, PhD, MHS

Program Director

Poverty, Gender and Youth Program, Population Council

tngo@popcouncil.org

Hannah E Briggs

MPH Candidate

Columbia University, Mailman School of Public Health

heb2133@cumc.columbia.edu

\section{Population Council}

IDEAS. EVIDENCE. IMPACT.

One Dag Hammarskjold Plaza

New York, NY 10017

www.popcouncil.org

\begin{abstract}
Large-scale emergencies, like the ongoing COVID-19 pandemic, demonstrate pervasive effects across multiple sectors. There is a continually growing body of evidence demonstrating gender and sex differences in COVID-19 disease, as well as its health, social, and economic impacts. While online resources have worked to compile this evidence, there is a need to evaluate and synthesize the available gender- and sex-disaggregated data related to COVID-19. This literature review will systematically assess and compile current literature and evidence from different disciplines. We will include peer reviewed articles, clinical studies and reports, and relevant working papers using secondary data analyses and primary research methodologies. We will synthesize and describe the evidence on multiple outcomes of interest, including gender and sex differences in mortality, severity, treatment outcomes, exposure to violence, mental health and psychosocial support needs, and economic insecurity with COVID-19. These results can be used to inform policy, identify research gaps, and support recommendations for priority interventions.
\end{abstract}

\section{BACKGROUND}

Lessons from past disease outbreaks, such as Zika and Ebola, illustrate the importance of incorporating a gender lens into disease response and prevention $(1,2)$. Public health emergencies can exacerbate existing inequalities and reveal how gender influences the health system and group vulnerabilities related to mortality, exposure, and access to care (3-5). There continues to be a missing gender lens in evidence and 


\section{POPULATION}

COUNCIL

Ideas. Evidence. Impact.

response related to the ongoing COVID-19 pandemic. Gender and sex differences can emerge in both direct consequences of disease (e.g., death, severity, and treatment outcomes) and indirect consequences due to disease response (e.g., loss of income, exposure to violence, and difficulty accessing resources). Understanding how these differ by gender and sex is essential in addressing needs and creating equitable interventions. To this end, it is vital to ensure collection and accessibility of gender- and sexdisaggregated data. Of the available data and literature found across multiple sectors (i.e., health, social, and economic), no one has collectively synthesized this body of evidence on the impacts of COVID-19 by gender and sex.

Research is rapidly emerging on sex and gender differences in relation to COVID-19. Global Health 50/50 is one resource tracking COVID-19 sex-disaggregated data, including mortality and diagnosed cases. While differences in prevalence appear to vary, a higher number of deaths from COVID-19 are occurring in males (6). This difference in mortality may represent sex-based biological differences or gendered differences (e.g., smoking practices) (3). Evidence is still developing on how hospitalizations, severity of disease, and treatment outcomes with COVID-19 differ by sex and gender. Data from Wuhan has suggested that men are at higher risk for severe cases with COVID-19 (7). Empirical evidence has also previously demonstrated that treatment outcomes with immunotherapies differ by sex, with immunotherapy notably being investigated in treatment of COVID-19 as it has been effective in managing infections like SARS-CoV and MERS-CoV in the past $(8,9)$.

On the other hand, women are at risk of frequent exposure as they make up approximately $70 \%$ of the frontline health and social sector workforce (3-5, 10-12). Women providing informal care within households may face additional exposure risk when caring for ill or elderly family members $(3,12,13)$. School closures are also expected to impact informal caregivers, where this additional responsibility may result in a loss of income and work outside the home (3). Household economic opportunity can be limited by travel restrictions and stay-at-home orders. As women are disproportionately represented in lowerpaid, part-time, and informal work, loss of income may differ by gender due to these restrictive measures $(3,12-15)$.

Instances of violence, such as gender-based violence (GBV) or intimate partner violence (IPV), typically increase during and after emergencies $(3,5,13,17)$. Cases rise as people experience heightened stress related to economic security and safety, in combination with being isolated due to quarantine or stay-athome orders (15). Reports of IPV have increased in several countries since responding to COVID-19 (5). France has reported a $30 \%$ increase in domestic violence cases since initiating lockdown on March $17^{\text {th }}$ (15), and during the month of February cases in China were three times higher compared to the prior year (18). People experiencing violence will have fewer options for support and additional challenges in access due to COVID-19 restrictions $(15,19)$. Groups that already report increased occurrence of IPV may be placed at further risk during this crisis. The lifetime risk of IPV for transgender people is estimated at 31$50 \%$ (20). COVID-19 may further increase this risk in a community that already has difficulty in accessing help and is underrepresented in data. The emotional, psychological, and physical burdens of a pandemic can negatively impact population wellbeing and increase need for mental health and psychosocial support. However, gendered differences in mortality, exposure to violence, and experiences of frontline health workers may alter the distribution of this burden and need for supportive services (10, $13,16)$.

If sexual and reproductive health (SRH) resources are redirected for other emergency measures, this can further restrict access to essential resources (e.g., contraceptives, termination services) $(5,10,15,21)$. This is especially relevant in settings that already have difficulty ensuring these services (14). In past 


\section{porpurarow COUNCIL \\ Ideas. Evidence. Impact.}

outbreaks, strained access to SRH care has contributed to increased child and maternal mortality (22). During the 2014-2015 Ebola outbreak, delays in care for pregnancy complications resulted in increased spontaneous abortions and hemorrhaging, among other negative outcomes (14). Supply chains for SRH and other hygiene items (e.g., menstrual health and hygiene management) can also be impeded during pandemics $(10,16)$. Accessibility of information on disease and prevention can differ by gender, related to literacy, educational attainment, internet access, and cell-phone ownership $(12,16)$. Rapid surveys from the UN have reported that women in Bangladesh and Pakistan are less likely to receive information about COVID-19 compared to men (16).

There have been many commentaries and perspective pieces on the gendered effects of COVID-19 and its response. Research and data are quickly being generated to inform policies, as well as social and health services, to address these differential impacts. Several online resources, such as the UN Women's Data Hub, Global Health 50/50, Data2X, and the Gender and COVID-19 Working Group from John Hopkins University, have worked to curate data and literature related to gender and sex during this pandemic. However, no collective synthesis of the current data has been done. In this review, we seek to understand available gender- and sex-disaggregated data and integrate current studies on the multisectoral impacts of COVID-19. By compiling and evaluating this information in one resource, we aim to create a resource that can be utilized by multiple disciplines and decisionmakers, periodically updated as evidence emerges, and referenced for insight on future policies and research in promoting health and gender equity.

\section{OBJECTIVE}

In this review, we will assess and synthesize currently available literature and data on the gender and sex differences of COVID-19, as well as impacts of this disease and its response measures across multiple outcomes, including health, social, economic, wealth, and education.

In evaluating this body of evidence, we aim to present findings that can be of use across multiple disciplines, identify current gaps in research, and identify priority interventions.

\section{METHODS}

\section{Selection Criteria}

We will be selecting peer-reviewed publications of secondary data analyses and primary quantitative, qualitative, and mixed methods research. Clinical studies and case reports in peer-reviewed journals on symptoms, treatment response, and hospitalizations will be included if data is gender- or sexdisaggregated. We will not be including studies or reports involving treatment with hydroxychloroquine. Due to the multidisciplinary lens of this review, we will also include published working papers in the selection process. Commentaries and perspective pieces will be excluded.

Publications must be COVID-19 specific and so, based on the timeline of this disease, publications prior to 2019 will be automatically excluded. Studies will not be limited based on language. Participants will consist of individuals of any gender, in all settings and across all ages, with no limitations on location or other demographic information.

\section{Outcomes of Interest}

This review will be focusing on the gendered impacts of COVID-19 across health, economic, and social factors. Outcomes of interest include but are not limited to: 
- Mortality

- Morbidity

- Risk of disease exposure

- Hospitalization

- Treatment response
- Reproductive health outcomes

- Exposure to violence

- Economic insecurity

- Disruption of education

- Psychosocial and mental health needs

\section{Search Strategy}

Our search will be conducted using the following electronic databases: PubMed/Medline, CENTRAL, PsycINFO, and Google Scholar. We will perform a hand search of sex-disaggregated data found in the Global Heath 50/50 database, and resources compiled by the Gender and COVID-19 Working Group from John Hopkins University. In addition, we will hand search reference lists from selected studies and systematic reviews identified in our search for other potentially eligible literature. Dates of studies will be constrained to 2019 and onwards based on emergence of COVID-19. Search terms may be modified as the body of evidence on COVID-19 grows (see table 1 for a draft of search terms).

\begin{tabular}{|c|c|c|}
\hline \multicolumn{3}{|l|}{ Table 1. Key search terms } \\
\hline \multirow{6}{*}{$\begin{array}{l}\text { covid-19 or } \\
\text { coronavirus or } \\
\text { CoV or } \\
\text { SARS-CoV-2 or } \\
\text { "covid-19 response*" or } \\
\text { "coronavirus response*" or } \\
\text { "SARS-CoV-2 response*" }\end{array}$} & \multirow[t]{6}{*}{ AND } & $\begin{array}{l}\text { sex or gender or wom! } \mathrm{n} * \text { or } \mathrm{m} ! \mathrm{n} \text { * or transgender or male or } \\
\text { female or "sex-disaggregated" or "gender-disaggregated" or } \\
\text { "gender analys*" or "gender equity" or "health equity" }\end{array}$ \\
\hline & & $\begin{array}{l}\text { "gender-based violence" or GBV or } \\
\text { "intimate partner violence" or IPV or "domestic violence" }\end{array}$ \\
\hline & & "psychosocial" or "mental health" or "stress" \\
\hline & & $\begin{array}{l}\text { "treatment" or "symptom*" or "mortality" or "morbidity" } \\
\text { "hospitalization" or "clinical management" "clinical outcomes" } \\
\text { or "exposure risk" }\end{array}$ \\
\hline & & $\begin{array}{l}\text { "economic securit*" or "economic status" or } \\
\text { "income loss" or "income securit*" or "job security*" or } \\
\text { "wealth" }\end{array}$ \\
\hline & & "school closure*" or "education* disruption" \\
\hline
\end{tabular}

\section{Methods for Selection}

Once potential studies are identified from the above search and any duplicate articles are removed, the residual titles and abstracts will be evaluated for relevance to our objective. We will obtain the full-texts of all potentially eligible studies, corresponding with study researchers when necessary. All decisions for selecting or excluding studies will be documented and outlined using a PRISMA diagram.

\section{Data Extraction}

Screening and data extraction will be performed by one reviewer, who will consult with a second reviewer based on concerns or deliberations. Disagreements will be resolved through discussion. Any 


\section{POPULATION}

COUNCIL

Ideas. Evidence. Impact.

gender- or sex-disaggregated data related to our outcomes of interest from selected studies will be collected. We will also extract data related to research design, location, participant characteristics, and other key study features.

\section{Assessing Study Quality}

Clinical, epidemiological and social science research studies will be evaluated and categorized as high, medium, or low quality based on the following criteria:

1. Clear research question(s)

2. Research methods consistent with standard practices

3. Sample size and justification

4. Appropriate analytic methods to answer research question(s)

5. Recommendations are clearly made based on analysis and findings from study

Studies will be considered high quality if they meet 4-5 of the above criteria, medium quality if they meet 3 , and low quality if they meet 2 or less. Clinical case reports and communications will be exempt from quality assessment based on the novel nature of COVID-19.

\section{Data Analysis and Synthesis}

We will present outcomes and relevant findings from selected studies using descriptive synthesis, noting common themes and recommendations from included literature. We will also be noting apparent gaps and ongoing needs in research, based on outcomes that are and are not being assessed in the selected articles. Our study limitations include a potential lack of uniformity for included methodology and outcome measures, given the broad nature of our objective.

\section{RESULTS}

\section{Proposed Tables and Figures}

Figure 1. Outline of study selection for literature review on the health, economic, and social effects of COVID-19 on gender and sex (adapted PRISMA flow diagram)

Sample Table 2. Overview and characteristics of included studies

\begin{tabular}{|l|l|l|l|l|}
\hline Study & Country/Region & $\begin{array}{l}\text { Participants \& } \\
\text { Methods }\end{array}$ & N & Study Quality \\
\hline
\end{tabular}

Sample Table 3. Summary of included studies with outcomes assessed and description of relevant findings related to COVID-19 and gender

\begin{tabular}{|l|l|l|}
\hline Study & Outcomes & Relevant Findings \\
\hline
\end{tabular}

Sample Figure 2. Distribution of outcomes of interest across selected studies on COVID-19 with genderand sex-disaggregated data 


\section{Number of Studies}

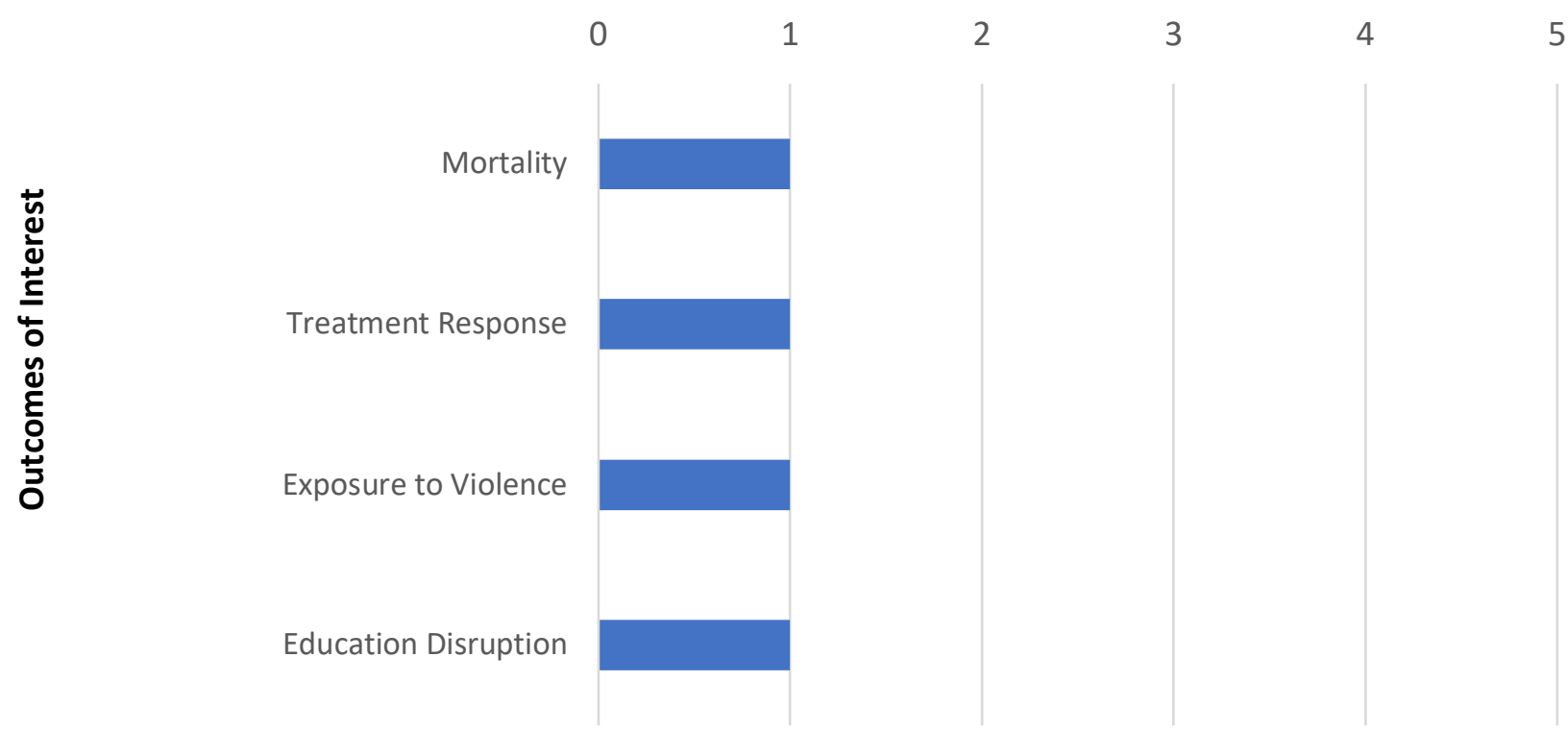

\section{IMPLICATIONS}

Gender continues to be a crucial influence in health, economic, and social outcomes. Global emergencies, like COVID-19, threaten to exacerbate and perpetuate gender inequalities, and require a gender lens for equitable response and interventions. This review synthesizes currently available gender- and sexdisaggregated data and evidence on COVID-19 and its impacts. We aim to periodically update this review as evidence continues to emerge. These results will have implications for policy recommendations and ongoing research in identifying priority issues, what gaps in knowledge remain, and recommendations for promoting health and gender equity in the midst and aftermath of COVID- 19.

\section{Declarations of Interest:}

The authors declare no potential conflict of interest.

\section{References:}

1. Smith, J. (2019). Overcoming the 'tyranny of the urgent': Integrating gender into disease outbreak preparedness and response. Gender \& Development, 27(2), 355-369. https://doi.org/10.1080/13552074.2019.1615288

2. Davies, S. E., \& Bennentt, B. (2016). A gendered human rights analysis of Ebola and Zika: locating gender in global health emergencies. International Affairs, 92(5), 1041-1060. https://doi.org/10.1111/1468-2346.12704

3. Wenham, C., Smith, J., \& Morgan, R. (2020). COVID-19: The gendered impacts of the outbreak. The Lancet, 395(10227), 846-848. https://doi.org/10.1016/s0140-6736(20)30526-2

4. Morgan, R., Ayiasi, R. M., Barman, D., Buzuzi, S., Ssemugabo, C., Ezumah, N., George, A. S., Hawkins, K., Hao, X., King, R., Liu, T., Molyneux, S., Muraya, K. W., Musoke, D., Nyamhanga, T., Ros, B., Tani, K., Theobald, S., Vong, S., \& Waldman, L. (2018). Gendered health systems: Evidence 


\section{POPULATION}

COUNCIL

Ideas. Evidence. Impact.

from low- and middle-income countries. Health Research Policy and Systems, 16(1), 58. https://doi.org/10.1186/s12961-018-0338-5

5. World Health Organization (WHO). (2020, May 14). Gender and COVID-19: advocacy brief. https://apps.who.int/iris/bitstream/handle/10665/332080/WHO-2019-nCoV-Advocacy brief-Gender2020.1-eng.pdf

6. COVID-19 sex-disaggregated data tracker, Global Health 50/50. (May 20, 2020). Global Health 50/50. Retrieved May 20, 2020, from https://globalhealth5050.org/covid19/sex-disaggregated-data$\underline{\text { tracker/ }}$

7. Jin, J.-M., Bai, P., He, W., Wu, F., Liu, X.-F., Han, D.-M., Liu, S., \& Yang, J.-K. (2020). Gender Differences in Patients With COVID-19: Focus on Severity and Mortality. Frontiers in Public Health, 8. https://doi.org/10.3389/fpubh.2020.00152

8. Klein, S. L., \& Morgan, R. (2020). The impact of sex and gender on immunotherapy outcomes. Biology of Sex Differences, 11(1). https://doi.org/10.1186/s13293-020-00301-y

9. Shanmugaraj, B., Siriwattananon, K., Wangkanont, K., \& Phoolcharoen, W. (2020). Perspectives on monoclonal antibody therapy as potential therapeutic intervention for Coronavirus disease-19 (COVID-19). Asian Pacific journal of allergy and immunology, 38(1), 10-18. https://doi.org/10.12932/AP-200220-0773

10. UNFPA. (2020). COVID-19: A Gender Lens, Protecting Sexual and Reproductive Health and Rights, and Promoting Gender Equality. https://www.unfpa.org/sites/default/files/resource-pdf/COVID19 A_Gender_Lens_Guidance_Note.pdf

11. Boniol, M., McIsaac, M., Xu, L., Wuliji, T., Diallo, K., \& Campbell, J. (2019, March). Gender equity in the health workforce: analysis of 104 countries. Working paper 1. Geneva: World Health Organization. https://apps.who.int/iris/bitstream/handle/10665/311314/WHO-HIS-HWF-Gender-WP12019.1-eng.pdf

12. CARE \& International Rescue Committee. (2020, April). Global Rapid Gender Analysis for COVID19. https://www.care.org/sites/default/files/global_rga covid rdm 3.31.20 final.pdf

13. CARE. (2020). Gender Implications of COVID-19 Outbreaks in Development and Humanitarian Settings. https://www.care-international.org/files/files/Gendered_Implications of COVID-19Full_Paper.pdf

14. Chattu, V. K., \& Yaya, S. (2020). Emerging infectious diseases and outbreaks: Implications for women's reproductive health and rights in resource-poor settings. Reproductive Health, 17(1), 43. https://doi.org/10.1186/s12978-020-0899-y

15. United Nations Entity for Gender Equality and the Empowerment of Women (UN Women). (2020). COVID-19 and Ending Violence Against Women and Girls. Retrieved from https://www.unwomen.org/-/media/headquarters/attachments/sections/library/publications/2020/issuebrief-covid-19-and-ending-violence-against-women-and-girls-en.pdf

16. Surveys show that COVID-19 has gendered effects in Asia and the Pacific. (2020, April 29). UN Women Data Hub. Retrieved May 10, 2020, from https://data.unwomen.org/resources/surveys-showcovid-19-has-gendered-effects-asia-and-pacific

17. Bradbury-Jones, C., \& Isham, L. (2020). The pandemic paradox: The consequences of COVID-19 on domestic violence. Journal of Clinical Nursing. https://doi.org/10.1111/jocn.15296

18. Usher, K., Bhullar, N., Durkin, J., Gyamfi, N., \& Jackson, D. (2020). Family violence and COVID-19: Increased vulnerability and reduced options for support. International Journal of Mental Health Nursing. https://doi.org/10.1111/inm.12735 


\section{POPULATION COUNCIL \\ Ideas. Evidence. Impact.}

19. O’Donnell, M., Peterman, A., \& Potts, A. (2020, April 3). A Gender Lens on COVID-19: Pandemics and Violence against Women and Children. Center For Global Development. Retrieved May 11, 2020, from https://www.cgdev.org/blog/gender-lens-covid-19-pandemics-and-violence-against-women-andchildren

20. Brown, T N.T., \& Herman, J. L. (2015). Intimate Partner Violence and Sexual Abuse Among LGBT People, A Review of Existing Research. UCLA School of Law, William's Institute. https://williamsinstitute.law.ucla.edu/wp-content/uploads/IPV-Sexual-Abuse-Among-LGBT-Nov2015.pdf

21. Tang, K., Gaoshan, J., Ahonsi, B., Ali, M., Bonet, M., Broutet, N., Kara, E., Kim, C., Thorson, A., \& Thwin, S. S. (2020). Sexual and reproductive health (SRH): A key issue in the emergency response to the coronavirus disease (COVID- 19) outbreak. Reproductive Health, 17(1), 59. https://doi.org/10.1186/s12978-020-0900-9

22. Menéndez, C., Lucas, A., Munguambe, K., \& Langer, A. (2015). Ebola crisis: The unequal impact on women and children's health. The Lancet Global Health, 3(3), e130. https://doi.org/10.1016/S2214$\underline{109 X(15) 70009-4}$ 